\title{
LA ROMA ESPAÑOLA DE MIGUEL DE ERCE XIMÉNEZ
}

\author{
Felipe Serrano Estrella \\ (Universidad de Jaén) \\ festrell@ujaen.es
}

\section{RESUMEN}

Miguel de Erce nos ofrece en su Prueva evidente de la predicación del Apóstol Santiago el Mayor en los reinos de España (Madrid: Alonso de Paredes, 1648) una interesante visión de la Roma española de la primera mitad del siglo XVII. Su estancia en la Urbe le permitió conocer esta compleja realidad, de ahí que los relatos legendarios emanados de diversos cronicones compartan lugar con interesantes noticias bien documentadas y casi olvidadas por la historiografía posterior. En un momento en el que se quería reforzar la identidad española en el corazón de la Cristiandad, el canónigo compostelano describe desde los lugares dedicados al apóstol Santiago, patrón de España, hasta las instituciones fundadas por españoles desde la Antigüedad hasta sus días, pasando por las intervenciones de los cardenales españoles en las iglesias de las que eran titulares. En el presente trabajo profundizamos en esta realidad, dejando de lado el estudio de las iglesias de San Giacomo degli Spanoli y Santa Maria di Monserrato, así como las casas de las órdenes mendicantes españolas, objeto de diferentes trabajos, y prestamos más atención al resto de instituciones que fomentaron esta identidad española en la Roma moderna.

PALABRAS CLAVE: Roma, Edad Moderna, Monarquía española, obras pías, cardenales, Miguel de Erce Ximénez.

\section{THE SPANISH ROME OF MIGUEL DE ERCE XIMÉNEZ}

\begin{abstract}
Miguel de Erce offers us in Prueva evidente de la predicación del Apóstol Santiago el Mayor en los reinos de España (Madrid: Alonso de Paredes, 1648) an interesting vision of Spanish Rome during the first half of the XVII ${ }^{\text {th }}$ Century. His stay in the city allowed him to learn about this complex reality, hence the legendary stories emanating from different «cronicones» share a place with interesting news well documented and almost forgotten by later historiography. At a moment when it was wanted to reinforce Spanish identity in the heart of Christianity, the canon describes from the places dedicated to the apostle Santiago, patron of Spain, to institutions founded by
\end{abstract}


Spaniards, from Antiquity to his days, passing by the interventions carried out by Spanish Cardinals in the churches where they were titular. In the present work we delve into this reality, setting aside the study of San Giacomo degli Spagnoly and Santa Maria di Monserrato, as well as the houses of the Spanish mendicant orders that have object of study in different works, and we pay more attention to the rest of institutions that promoted Spanish identity in Modern Rome.

KEY WORDS: Rome, Modern Age, Spanish Monarchy, pious foundations, cardinals, Miguel de Erce Ximénez.

\begin{abstract}
$* * *$
Las iglesias y lugares píos nacionales, que tiene oi en Roma la Monarquía Española son innumerables por serlo las gentes, Reinos, i provincias, que están debaxo de su dominio, i tener todas en Roma estas iglesias, i Hospitales. Especialmente ai de los Reinos de España tres iglesias ilustres con sus Hospitales: la de S. Antonio de Nación Portuguesa, que demoliendo la antigua la ha levantado ahora a fundamentis; la de nuestra Señora de Monserrate donde concurren las tres Coronas de Aragón, Valencia i Cataluña; i la de Santiago, por su excelencia de Nacional nuestra llaman de los Españoles. Esta es la matriz desta Nación'1.
\end{abstract}

El que fuera canónigo de las catedrales de León y Santiago de Compostela, así como capellán real en Toledo, el doctor Miguel de Erce Ximénez, describió a través de su Prueva evidente de la predicación del Apóstol Santiago el Mayor en los reinos de España (1648) los espacios dedicados al apóstol en Roma y subrayó su relación con los españoles que se hallaban en la Urbe ${ }^{2}$. Su relato nos ofrece un interesante recorrido por la Roma española de la primera mitad del siglo XVII, ciudad que conoció de forma directa pues tuvo que atender «negocios graves de las Indias tocantes al patrimonio real» ${ }^{3}$. Además de los espacios santiaguistas y de las tres citadas iglesias de los reinos peninsulares, Erce describe las fundaciones de santos españoles, las casas de las

\footnotetext{
${ }^{1}$ Erce Ximénez Miguel de, Prueva evidente de la predicación del apóstol Santiago el Mayor en los Reinos de España (Madrid: Alonso de Paredes, 1648), 202v. Sobre la Roma española: Dandelet Thomas James, Spanish Rome 1500-1700 (New Haven-London: Yale University Press, 2001); Visceglia Maria Antonietta: "Vi è stata una «Roma spagnola»", Roma moderna e contemporanea 11 (2003), 313-323; "Rome e la Monarchia Cattolica nell'età dell'egemonia spagnola in Italia: un bilancio storiografico", en Roma y España un crisol de la cultura europea en la Edad Moderna, Actas del Congreso, Real Academia de España en Roma, 8-12 de mayo de 2007, ed. Carlos José Hernando Sánchez (Madrid: Sociedad para la Acción Cultural Exterior, 2007, vol. I), 53-77 y Roma papale e la Spagna. Diplomatici nobili e religiosi tra due corti, (Roma: Bulzoni, 2010). Tampoco podemos dejar de citar a Espadas Burgos Manuel, Buscando a España en Roma (Barcelona-Madrid: Lunwerg, 2006).

${ }^{2}$ A ellos les dedica el «Tratado segundo en que se refieren las iglesias que hay en Roma dedicadas a nuestro Apóstol Santiago, las calidades i excelencias dellas. Pruévase, que la de nuestra nación es de fundación real, i se manifiesta que ai muchas fundaciones grandes de Españoles en aquella sagrada Ciudad».

${ }^{3}$ Así lo reconoce él mismo en la dedicatoria que hace a Felipe IV en su obra.
} 
órdenes mendicantes, fundaciones pías y recoge también un buen número de las acciones de promoción artística desarrolladas por los cardenales españoles en la Urbe. Las palabras que abren este trabajo resumen parte de la realidad de las iglesias vinculadas a la corona española en la Roma moderna y subrayan la identidad nacional que se creó en torno a ellas ${ }^{4}$. Efectivamente, las iglesias y lugares píos de raíz hispánica eran muchos y además de los templos y hospitales citados por Erce estaban: Santi Ambrogio e Carlo (lombardos), San Francesco di Paola (calabreses), Santo Spirito (napolitanos), Santa Maria d'Itria o di Constantinopoli (sicilianos) y la ya citada por Erce de Sant' Antonio dei Portoghesi.

Como bien afirma el canónigo compostelano, la principal de estas iglesias era la dedicada a los santos Ildefonso y Santiago, que contaba con el privilegio de nacional, y recibía el título San Giacomo degli Spagnoli. Desde tiempos de Felipe II, en el marco de un proceso de intervención de la corona sobre la institución, se debatía en torno a su antigüedad, intentando ubicar sus orígenes en una fundación creada por el infante Enrique de Castilla (1230-1303), hijo de Fernando III $^{6}$. La realidad era bien distinta y su creación había sido impulsada por Alfonso de Paradinas (ca. 1458), obispo de Ciudad Rodrigo. Durante el reinado de los Reyes Católicos, la iglesia había recibido un particular impulso de la mano de su gobernador, el cardenal Bernardino López de Carvajal (1456-1523), que a partir de 1491 la condujo hacia una época de gran esplendor, como prueba la edificación de la magnífica portada hacia la representativa Piazza Navona ${ }^{7}$ En torno a 1520, el templo fue escenario de importantes reformas

\footnotetext{
4 Para el estudio de las fundaciones españolas en Roma es necesario partir de los siguientes estudios: Aguado Francisco, Las fundaciones de España en Roma y las leyes italianas de desamortización (Roma: Tipografía Romana, 1875). En él aborda las instituciones sobre las que la corona o las órdenes religiosas españolas tenían derecho de propiedad, concluyendo que, si bien algunas poseían protección real, ninguna fue creada y dotada por la monarquía española y que, por tanto, no ejercía un verdadero ius patronatus sobre ninguna. No obstante, subraya la singularidad de San Pietro in Montorio. Aguado, Las fundaciones, 6-7. Otra obra de referencia fue la de Tormo Elías, Monumentos de españoles en Roma, y de portugueses e bispanoamericanos (Madrid: Ministerio de Asuntos Exteriores, 1942 -ed. Italiana 1940-).

${ }^{5}$ En referencia a las iglesias nacionales de Aragón y Castilla: Fernández Alonso Justo: "Las iglesias nacionales de España en Roma. Sus orígenes", Anthologica Annua 4 (1956), 9-96 y "Santiago de los Españoles de Roma en el siglo XVI", Anthologica Annua, 6 (1958), 266-285. Más recientes son los trabajos de: García Hernán Enrique, "La iglesia de Santiago de los Españoles en Roma: trayectoria de una institución", Anthologica Annua 42 (1995), 297-363. Barrio Gozalo Maximiliano, "La Iglesia y Hospital de Santiago de los Españoles de Roma y el patronato real en el siglo XVII", Investigaciones Históricas: Época moderna y contemporánea 24 (2004), 53-76 y Vaquero Piñeiro Manuel: "L'ospedale della nazione castigliana in Roma tra medioevo ed età moderna", Roma moderna e contemporánea 1 (1993), 57 81 y "Una realtá nazionale composita: comunità e chiese «spagnole» a Roma", en Roma capitale (14471527), Atti del IV convegno di studio del Centro di Studi sulla Civiltà del Tardo Medioevo, 27-31 ottobre 1992, ed. Sergio Gensini (San Miniato, Pacini, 1994), 473-491.

6 Tanto Miguel de Erce como más tarde García del Pino lo defendieron; este último en su Discorso sopra la fondazione di S. Giacomo degli Spagnoli, che sia regia e fondata dal infante Don Henrico di Castiglia en non da Alfonso di Paradinas, 1754, custodiado en el Archivo de la Iglesia Nacional Española en Roma, Leg. 1226.

${ }^{7}$ No podemos olvidar las ceremonias que se celebraron en este templo con motivo de la muerte de Isabel la Católica que fueron presididas por el citado cardenal y embajador de los Reyes Católicos. Vaquero Piñeiro Manuel, "I funerali romani del principe Giovanni e della regina Isabella di Castiglia.
} 
arquitectónicas, entre las que destacaron la construcción de la capilla de Santiago, obra de Antonio da Sangallo el Joven, que había sido promovida por el cardenal Jaime Serra (ca. 1430-1517) y que se hallaba presidida por la escultura de Jacopo Sansovino (ca. 1525) ${ }^{8}$. En 1551, Constantino del Castillo, deán de Cuenca y arcediano de Játiva, fundaba la capilla de la Asunción que sería decorada por Gaspar Becerra; mientras que la capilla Herrera recibía las obras de Annibale Carraci y quedaba dedicada a San Diego de Alcalá9.

Los orígenes de la iglesia de Santa Maria di Monserrato los encontramos en un pequeño hospicio que acogía a los peregrinos de la corona de Aragón y que se había fundado a mediados del siglo XIV. Junto a él se erigió la iglesia de San Nicolás. A finales del siglo XV y en los primeros años de la centuria siguiente, la institución aragonesa vivió un momento de esplendor que se tradujo en la construcción de un nuevo templo trazado por Antonio da Sangallo el Viejo (1506). Dedicado a la Purificación y a Nuestra Señora de Monserrat, estas serían las dos fiestas principales que se celebrarían en la casa ${ }^{10}$.

Junto a estas iglesias estaban las fundaciones de los mendicantes españoles que se fueron erigiendo para dar una mayor visibilidad a las órdenes, especialmente a las nacidas de las reformas, y para garantizar una morada a sus frailes mientras realizaban algún tipo de gestión ante la curia pontificia. Estas casas se convirtieron en residencias estables gracias al apoyo no solo de sus connacionales sino también del resto de habitantes de la ciudad. Con ellas se evitaba que los frailes se alojaran en lugares poco apropiados y se reducía el tan temido gasto de la estancia romana ${ }^{11}$. El Capo le Case y los alrededores de la Piazza di Spagna acogieron el mayor número de fundaciones como Santi Gioacchino e Anna alle Quattro Fontane (carmelitas descalzos, 1597), San Giuseppe a

Rituale politico al servizio della monarchia spagnola", en Roma di fronte all'Europa al tempo di Alessandro $V I$, eds. Maria Chiabó, Silvia Maddalo, Massimo Miglio y Anna Maria Oliva (Roma: Ministero per i beni e le attività culturali, 2001, vol. 2), 641-655.

8 «La efigie de Santiago, que está en altar de su capilla, es de inestimable valor su exquisita i delicada labor de suma perfección: es de mármol finísimo, cuerpo entero, en postura que va caminando; confieso que quanto más la miraba me admiraba más. Baste decir que un valiente escultor pasaba allí estos años grandes ratos considerándola i hablando con ella como si fuera hombre vivo le dezía: que por qué no andaba y hablaba, tanta es la excelencia desta venerable efigie de nuestro sagrado apóstol Santiago el Zebedeo». Erce, Prueva, 202.

${ }^{9}$ Carrió-Invernizzi Diana, "Santiago de los Españoles en Plaza Navona (Siglos XVI-XVII)", en Piazza Navona, ou Place Navone, la plus belle \& la plus grande, ed. Jean François Bernard (Roma: École Française de Rome, 2014), 635-655.

${ }^{10}$ Además de algunos de los títulos citados en la nota 4, recomendamos la visión general que sobre este templo nos ofrecen: Fernández Alonso Justo, S. Maria di Monserrato (Roma: Marietti, 1968) por Carrió-Invernizzi Diana, "Los catalanes en Roma y la iglesia de Santa María de Montserrat (1640-1670)", Pedralbes 28 (2008b), 571-584 y Rivera de las Heras José Ángel, La Iglesia Nacional Española de Santiago y Montserrat de Roma (Madrid: Instituto Español de Historia Eclesiástica, 2020).

11 Para las casas de mendicantes en Roma véanse: García Cueto David, "El mecenazgo de los embajadores de Felipe IV en los conventos de Roma: política, prestigio y devoción en la Ciudad Eterna durante el siglo XVII”, en La corte en Europa. Política y religión (siglos XVI-XVIII), ed. José Martínez Millán et alii (Madrid: Polifemo, 2012, vol. II), 1661-1697 y Serrano Estrella Felipe, "Conventos y hospicios de las órdenes mendicantes española en la Roma moderna”, BSAA Arte 84 (2018): 219-254. 
Capo le Case (único monasterio de monjas, carmelitas descalzas, 1598), San Carlo alle Quattro Fontane (trinitarios descalzos, 1599), Santi Ildefonso e Tommaso da Villanova (agustinos recoletos, 1619), Sant' Isidoro a Capo le Case (franciscanos recoletos, 1622), la Madonna di San Giovannino (mercedarios descalzos, 1628) y Trinità degli Spagnoli (trinitarios, 1730). Fuera de este ámbito se situarían las establecidas en espacios tan simbólicos como San Pietro in Montorio (franciscanos, ca. 1472), Sant' Adriano in Campo Vaccino (mercedarios, 1589) y Santi Quaranta Martiri e San Pasquale Baylon (franciscanos alcantarinos, 1736). El resto de órdenes solía tener un «cuarto español» en casas como Santa Sabina (dominicos), San Francesco di Paola (mínimos) o en Santa Maria in Aracoeli (franciscanos).

Los testamentos consultados, especialmente los del siglo XVII, constatan que existió una vinculación efectiva de los connacionales y estas casas mendicantes, además de con las iglesias nacionales. Pese a enterrarse en estas últimas o en las que actuaban como sus parroquias, especialmente San Lorenzo in Lucina y San Nicola a Capo le Case, los españoles residentes en Roma recordaban a los frailes y monjas con limosnas, el encargo de misas o con otras muchas donaciones, siendo las ramas recoletas las que levantaban un mayor favor. También tenemos constancia de que los clérigos españoles en Roma acudían a celebrar a los templos emparentados con su nación, si bien, según si eran de Aragón o de Castilla, tenían preferencia por alguna de las dos iglesias, para las casas mendicantes lo hacían de manera indistinta ${ }^{12}$.

Junto a esta realidad, desde finales del siglo XVI existió un interés por extender la identidad española en Roma más allá de las citadas iglesias nacionales y de las casas mendicantes y se apostó por abrirla a otras muchas instituciones que, en determinadas ocasiones, hundían sus raíces en los principios del cristianismo. Autores como el propio Miguel de Erce contribuyeron a estos fines y situaron los primeros pasos «en las fundaciones de S. Dámaso en Roma i se refieren muchísimos breviarios en que se lee que fue español San Lorenzo, i los Himnos que Urbano VIII le celebra por nuestro» ${ }^{13}$. La primera fue la de San Lorenzo in Damaso, templo al que el cardenal Riario (1461-1521) cambió considerablemente su morfología al edificar el Palazzo della Cancelleria (fig. 1). Ya fuera por esta tradición o por su ubicación en las proximidades de los espacios más hispánicos de la ciudad, lo cierto es que la iglesia de San Lorenzo

\footnotetext{
12 Juan Vaquer, canónigo doctoral de Zaragoza, que vivía en la plaza de la Trinidad de Monte Pincio, rione de Campo Marzio, envió a España «un terno de lastra pingerant». El doctoral afirmaba que era suyo y que se lo había puesto en varias ocasiones. Los testigos así lo indicaron, especificando que lo usaba «en particular a la de nuestra Señora de Montserrat y de San Ildefonso de Padres Agustinos descalços y de Santa Ana de padres Carmelitas descalços, y de San Juan niño de padres mercenarios descalços, en las quales dicho señor canónigo por su devoción solía celebrar la misa». Archivio Storico Capitolino di Roma (ASCR), Archivio Generale Urbano, Sezione I, Not. Juan Caballero, vol. 202, 16 de octubre de 1665. Incluso, prelados como Luis III de Torres (1551-1608), aunque nacido en Roma, de fuertes raíces hispánicas, celebraron su primera misa en lugares tan cercanos a España como la basílica de Santa Maria Maggiore. Soto Artuñedo Wenceslao, "La familia malagueña «De Torres» y la Iglesia”, Isla de Arriarán 19 (2002),180.

${ }^{13}$ La historiografía que materializa el deseo por construir esta identidad nacional se desarrolla, principalmente, desde finales del siglo XVI y sobre todo en la siguiente centuria. Erce, Prueva, Parte II, Trat., II. Cap. IV.
} 
atrajo un buen número de donaciones de españoles en Roma y de fuera de ella, como la realizada por Teresa Enríquez (ca. 1450-1529), matrona de las españolas, que «Fue devotísima del Santísimo Sacramento i así adornó, ilustró i dotó su capilla en la iglesia de nuestro glorioso S. Lorenzo in Damaso a lo grande i hermoso en 1508». A San Dámaso se atribuiría la fundación de otras iglesias como la de Santa Rufina y Secunda, Santa Anastasia, San Mauro, San Diógenes, San Félix o San Adauto ${ }^{14}$. Precisamente, los templos de Santa Rufina y Santa Anastasia sí tendrían relación con España; el primero acogió a los mercedarios españoles hasta su traslado a Sant' Adriano in Campo Vaccino en 1589 y del segundo fue titular el cardenal Bernardo de Sandoval y Rojas (1546-1618) que alentó una gran reforma.

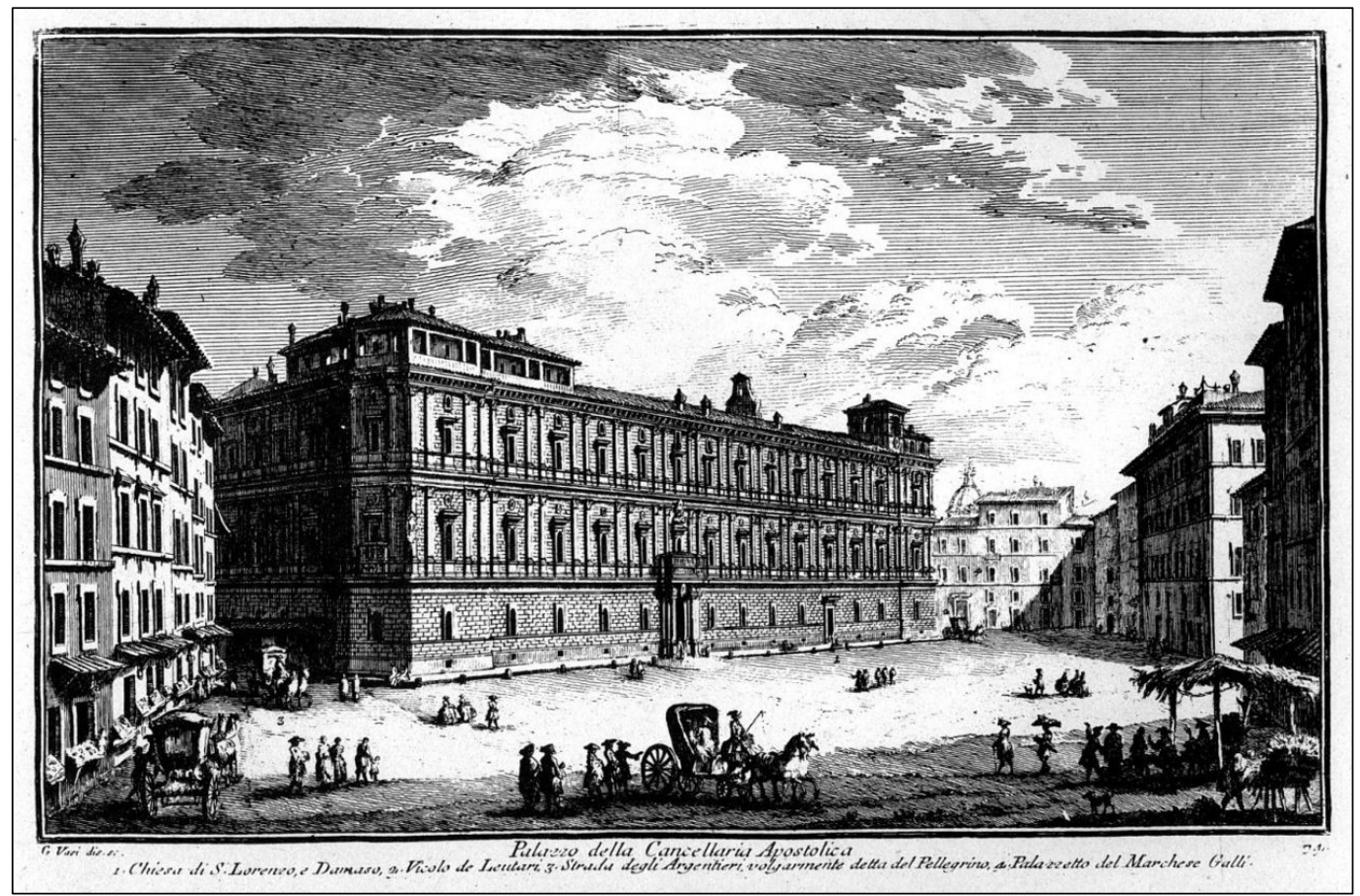

Figura 1. Giuseppe Vasi, Palazzo della Cancelleria Apostolica, 1747-1761.

Miguel de Erce también ensalzó las obras de los dos papas Borgia a las que dotó del sello español. Calixto III (1378-1458) restauró, tras un incendio, la iglesia de Santa Prisca en el Aventino, aunque Erce le atribuye la fundación; mientras que Alejandro VI (ca. 1431-1503) engrandeció el Palacio Apostólico Vaticano y los hospitales della Consolazione y de San Rocco. Junto a él, destacó a dos cardenales valencianos: Juan López (1454-1501), datario del papa, que costeó la magnífica fuente de la Piazza di Santa Maria in Trastevere, frente a su residencia, y Juan de Castro (14311506), que promovió una bella sepultura en Santa Maria del Popolo (fig. 2) «entrando por

\footnotetext{
14 Miguel de Erce hará de Santa Sabina una fundación española, concretamente de Santo Domingo de Guzmán.
} 
la puerta grande de medio día a la mano derecha»; iglesia en la que también se enterró el burgalés Juan Ortega Gomieli (1462-1503), datario de Alejandro VI, concretamente junto a la puerta de la sacristía, junto a la sepultura del también valenciano Pedro Guillermo Roca, arzobispo de Salerno entre 1471-1485. No podemos olvidar que, a finales del siglo XV, Santa Maria del Popolo tuvo una especial relación con la corona española y que Bernardino López de Carvajal celebró allí la toma de Baza ${ }^{15}$.

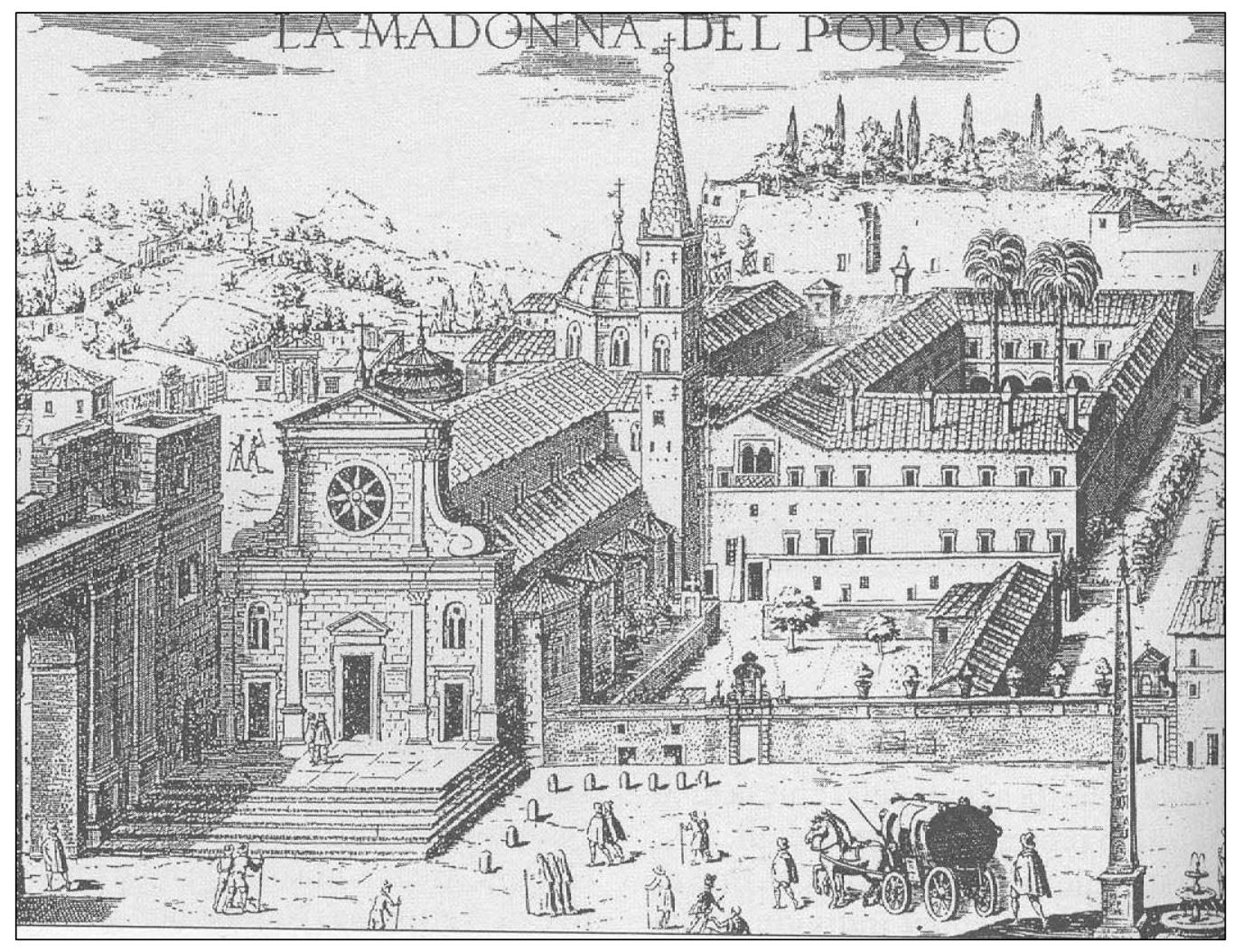

Figura 2. Giovanni Maggi, La Madonna del Popolo, 1625.

Otro de los templos que desde antiguo estaba vinculado a la nación española era la basílica de Santa Maria Maggiore (fig. 3), cuya protección fue encargada a los reyes de España y que fue testigo del simbólico gesto de la donación del primer oro traído de Indias y utilizado para la decoración de su artesonado. Los embajadores asistían con gran pompa a la fiesta de la Natividad de la Virgen y Felipe III le concedió una sustanciosa pensión anual, gesto que el cabildo agradeció dedicándole un epitafio en las puertas del sagrario ${ }^{16}$. Esta basílica acogió importantes fundaciones de españoles, por ejemplo, la realizada por el cardenal Francisco de Toledo (1532-1596), y sobre

${ }^{15}$ Goñi Gaztambide José, "Bernardino López de Carvajal y las bulas alejandrinas", Anuario de Historia de la Iglesia 1 (1992), 100.

${ }^{16}$ Erce, Prueva, 227-227v. 
todo la creación en 1647 de la Obra Pía de España por Felipe IV, que tuvo como consecuencia la escultura del monarca situada en el nártex y diseñada por Bernini ${ }^{17}$. Esta fundación tendría su correlato en la pensión anual de la Chinea en San Pietro, instituida en 1658, y en el protectorado que se ejerció en San Giovanni in Laterano, mecanismos que reforzaron la estrecha relación de las basílicas mayores con la corona española ${ }^{18}$.

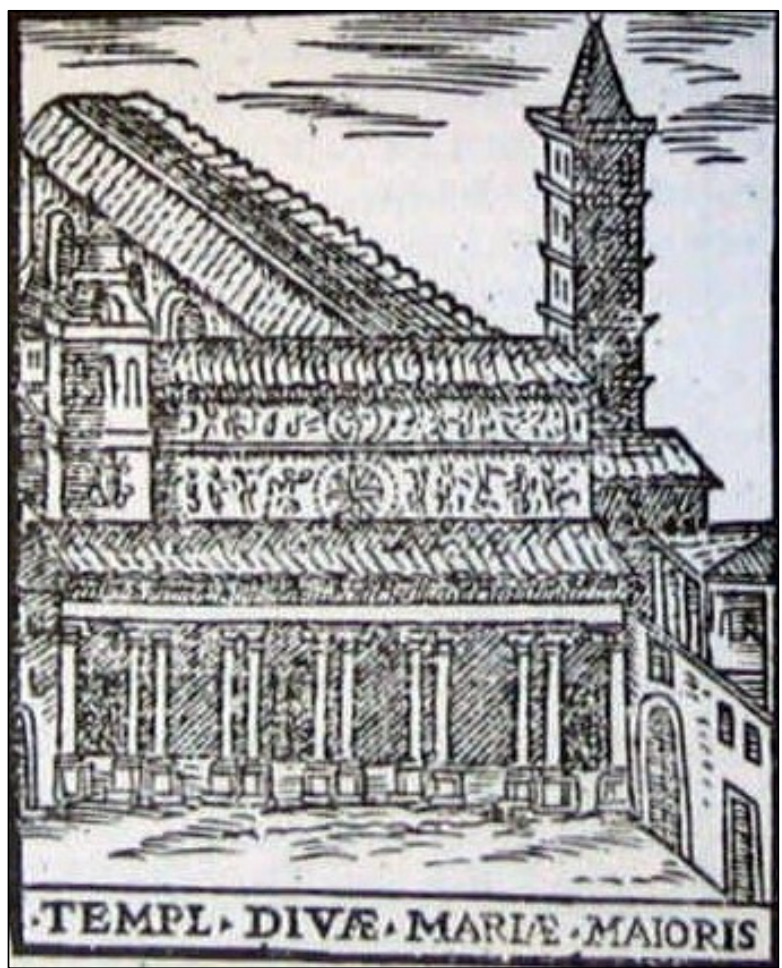

Figura 3. Girolamo Francino, Templ. Divae Mariae Maioris, 1588.

${ }^{17}$ En relación con la fundación del cardenal Toledo: Fernández Alonso Justo, "El cardenal Francisco de Toledo, S. J., y su fundación en Santa María la Mayor", Anthologica annua 37 (1990), 363380. Existe una amplia bibliografía sobre la escultura de Felipe IV: Ostrow Steven F., "Gianlorenzo Bernini, Girolamo Lucenti and the Statue of Philip IV in S. Maria Maggiore. Patronage and politics in Seicento Rome", Art Bulletin 73 (1991), 89-118 o los trabajos más recientes de Carrió-Invernizzi Diana, "La estatua de Felipe IV en Santa Maria Maggiore y la embajada romana de Pedro Antonio de Aragón (1664-1666)", Roma moderna e contemporanea revista interdicisplinare di storia 1-3 (2007), 255-270 y de la misma autora El gobierno de las imágenes. Ceremonial y mecenazgo en la Italia española de la segunda mitad del siglo XVII (Madrid: Tiempo Emulado, 2008a), 186-192; también el trabajo de Bodart Diane H., "Le guerre des statues. Monuments de rois de France et d'Espagne à Rome au XVIIe siècle", en Roma y España un crisol de la cultura europea en la Edad Moderna, Actas del Congreso, Real Academia de España en Roma, 8-12 de mayo de 2007, ed. Carlos José Hernando Sánchez (Madrid: Sociedad para la Acción Cultural Exterior, 2007, vol. II), 686-688.

${ }^{18}$ Sobre la intervención española en estas basílicas durante el gobierno de Felipe IV: CarrioInvernizzi, El gobierno, 164-192. 


\section{UNA DEVOCIÓN IDENTIFICADA CON LA NACIÓN ESPAÑOLA. IGLESIAS Y CAPILLAS DEDICADAS AL APÓSTOL SANTIAGO EN ROMA}

Desde comienzos del siglo XVII existió una tendencia interesada a considerar que todos los lugares de culto dedicados al apóstol Santiago en Roma tenían una vinculación directa con España. En determinados casos, algunos de los constructores de esta realidad, como Miguel de Erce, se esforzaron para cimentar estos orígenes hispánicos ${ }^{19}$. Los alrededores de la basílica de San Pietro acogieron desde finales de la Edad Media a un buen número de españoles, de ahí que, aparte del fervor que generaba la Madonna della Febbre (fig. 4) ${ }^{20}$, los miembros de esta colonia encontraran en el corazón del Borgo Nuovo un templo dedicado a Santiago, devoción que les era estrechamente familiar ${ }^{21}$. De igual modo, en esta misma zona, pero a espaldas de la basílica petrina, se encontraba la iglesia de Santa Marta que custodiaba una capilla dedicada a Santiago. Esta se hallaba presidida por una representación de la Aparición de la Virgen al apóstol que se tendría como una Virgen del Pilar, devoción que ya estaba presente en la propia basílica de San Pietro, concretamente en el altar llamado de la Madonna della Colonna ${ }^{22}$. La vinculación de Santa Marta con Santiago no quedaría solo en la citada capilla, sino que además el papa Gregorio XIII (1502-1585) aplicó a esta iglesia las mismas indulgencias que tenían la catedral compostelana y el templo del hospital de San Giacomo degli Incurabili23. Asimismo, Benedicto XIII (1649-1730) concedió la custodia de Santa Marta a los trinitarios españoles de San Carlino, labor que ejercieron entre 1726 y $1789^{24}$.

\footnotetext{
${ }^{19}$ Sobre la devoción a Santiago en Roma y con la nómina completa de templos dedicados al apóstol: Vázquez Santos Rosa, "Primeras conclusiones sobre el culto y la iconografía de Santiago el Mayor en la ciudad de Roma", Archivo Español de Arte 329 (2010), 1-22.

${ }^{20}$ Recordada por Sebastiano del Piombo a Ferrante Gonzaga a través del agente de los Gonzaga en Roma, Niccolo Sernini: «una nostra donna ch'avesse il figliolo morto in braccio a guisa di quella dela Febre, il che li spagnoli per parer buon cristiani et divoti sogliono amare questi cose pietose». Falomir Miguel, "Sebastiano and «Spanish taste»" en Sebastiano del Piombo, 1485-1547, Cat. Exp. Palazzo Venezia, Roma, 8 de febrero-18 de mayo de 2008, ed. Claudio Strinari y Bernd Wolfgang Lindermann (Milán, Federico Motta, 2008), 67.

${ }^{21}$ Erce, Prueva, 227v. Entre las iglesias dedicadas a Santiago que no tenían vinculación directa con los españoles estaban las de dos monasterios de monjas. Una en la Lungara y la otra de franciscanas junto a la Fontana di Trevi. También cita la de San Eligio de los Herreros o Plateros que tuvo por invocación antigua la de Santiago y su efigie estaba en el altar mayor; esta iglesia conservaba la caja en la que se trajo desde Jerusalén la Santa Faz «o vulto santo que dizen en Roma». Además, quedaba memoria de otras iglesias perdidas como la que se encontraba en Piazza Madama o en el propio Coliseo. Ibídem, 228.

22 Erce, Prueva, 234v-235. A esta capilla le dedica un capítulo aparte. «Veese i se venera pintada en Roma esta sagrada historia, especialmente en nuestras Iglesias Nacionales de Santiago i Montserrate en capillas, i altares formados, i son muchas las pinturas i estampas abiertas, e impresas allí con licencia de los superiores, en que se adora la Madre de Dios sobre la columna, el Apóstol Santiago de rodillas encomendándose a su protección i a otra parte los discípulos en la misma postura». Ibídem, 244v-245.

${ }^{23}$ Erce, Prueva, 235.

${ }^{24}$ Fue demolida en 1930. Elías Tormo recordaba, a partir de Forcella, la lápida de Jerónimo de Salas (+1729) que allí se conservaba. Tormo, Monumentos, 121. Véase también: Anselmi Alessandra, Le chiese
} 


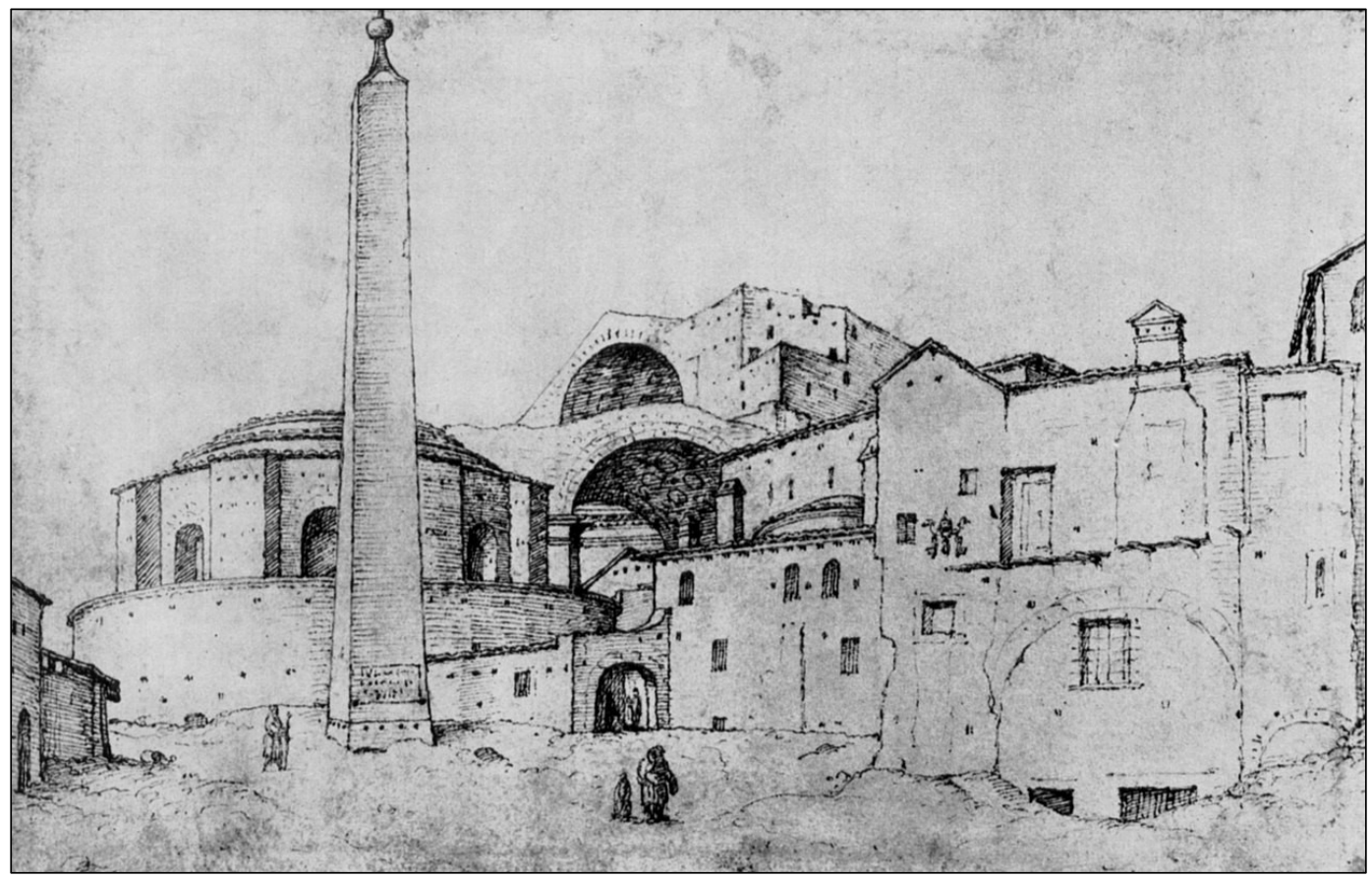

Figura 4. Maarten van Heemskerck, Santa Maria della Febbre, 1532.

Una de las instituciones que se intentó «españolizar» desde sus orígenes fue San Giacomo degli Incurabili o in Augusta (fig. 5), esta última denominación por hallarse junto al mausoleo de Augusto y, a su vez, muy próxima al hospital de San Rocco, fundado por Alejandro VI. Miguel de Erce afirmó que «ai tradición constante entre los de nuestra Nación, que fueron della los primeros fundadores deste lugar pío». Asimismo, aseguraba que la vinculación con sus connacionales había venido a menos y recogía un hecho acontecido en su tiempo, concretamente con el doctor portugués Oduardo Pinto, abogado de aquella corte, que se quejaba del boicot que había sufrido en sus intentos de gobernar la cofradía que se encargaba de regir el hospital y su templo, ya que sus miembros no querían que un español la dirigiera, olvidando que «fuesen españoles los primeros fundadores de la obra pía, que es voz asentada entre nuestros nacionales, lo qual se confirma de aver sido españoles algunos de los del gobierno hasta estos días» ${ }^{25}$.

spagnole nella Roma del Seicento e del Settecento (Roma: Gangemi, 2012), 70; Bossi Gaetano, La Chiesa di Santa Marta al Vaticano. Monografia storica (Roma: Tipografia Poliglotta della S. C. di Propanda, 1883) por Pietrangeli Carlo, "Ricordo di una chiesa distrutta: Santa Marta al Vaticano", Bollettino Monumenti Musei e Gallerie Pontificie” 5 (1984), 91-111 y Aliaga Asensio, Pedro, "Alle origini di Santa Marta", L'Osservatore Romano (29.1.2016), 4.

${ }_{25}$ Pese a estos vínculos con la nación española, la fábrica arquitectónica no era cosa de los españoles, sino que fruto del empeño del cardenal Antonio Maria Salviati (1537-1602). Erce, Prueva, 228. 


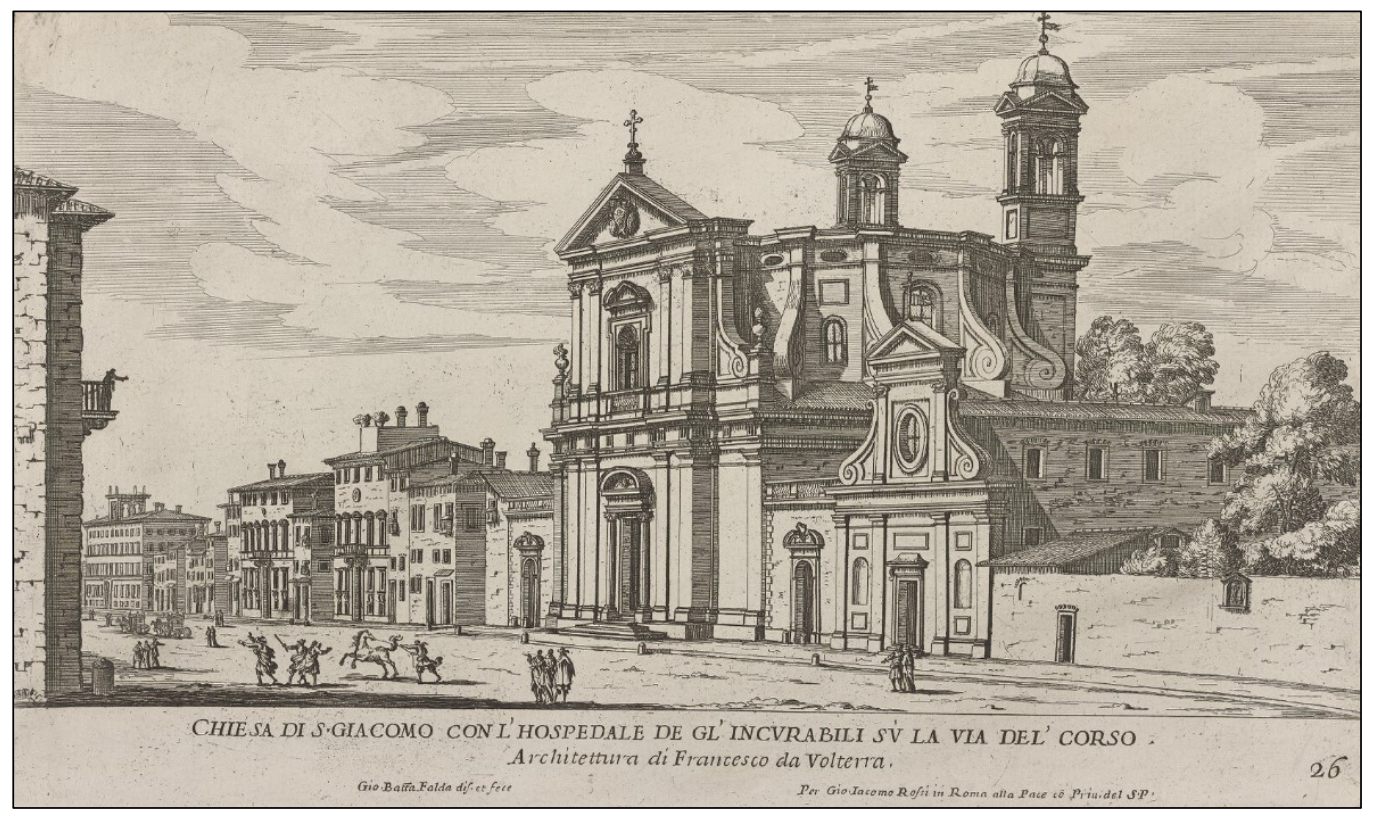

Figura 5. Girolamo Rossi (1682-1762), a partir de Giovanni Battista Falda. Chiesa di S. Giacomo con l'Hospedale degl' Incurabili su la Via del Corso. Architettura di Francesco da Volterra.

Pese a esta argumentación, en realidad, la fundación de San Giacomo había tenido lugar en 1339 gracias a un legado del cardenal Pietro Colonna (1260-1326). Sin embargo, sí era cierta la vinculación defendida por los españoles, aunque se encontraba muy olvidada, de ahí la necesidad de fomentar intervenciones sobre esta institución. La iglesia del hospital, que levanta su fachada hacia el Corso, era calificada de «excelente» por su singular planta central que permitía escuchar la misa desde todos los puntos, lo que causó notable impacto en el cardenal Bernardo de Sandoval y Rojas que hizo «traer el modelo el Señor Cardenal Arçobispo don Bernardo de Sandoval i Rojas i labró otra semejante a ella junto con el monasterio que fundó en Alcalá de Henares para monjas de la Orden de S. Bernardo». Además, en ella fundó y dotó dos misas perpetuas el cardenal Bartolomé de la Cueva (1499-1562), hijo de los duques de Alburquerque, administrador apostólico de Avellino y Frigento (1548-1549) y de Manfredonia (15601562) y virrey de Nápoles, que un primer momento ordenó enterrarse en los umbrales de San Giacomo degli Spagnoli ${ }^{26}$.

Como hemos adelantado, la presencia española era mucho más patente en otro espacio del hospital, concretamente en la iglesia situada a sus espaldas, Santa Maria in Porta Paradisi. Tormo recoge que fue construida entre 1519 y 1532 con proyecto de Antonio da Sangallo el Joven y gracias a la financiación del canónigo Antonio de Burgos (†1525), que se enterraría en ella. La relación entre el templo y la nación española fue constante; baste recordar que entre 1644 y 1662 se renovó su decoración gracias al legado del médico Matteo Caccia y se desplegó un programa iconográfico en

\footnotetext{
${ }^{26}$ Ibídem, 228.
} 
el que se destacaba a Santiago Matamoros como defensor de la Inmaculada Concepción. Alessandra Anselmi asegura que su mentor tuvo que ser el clérigo español Pedro de Castro, miembro de la cofradía hospitalaria ${ }^{27}$.

Junto a estas iglesias dedicadas al apóstol, y en las que se quiso hallar un referente para la identidad nacional española, existieron también capillas que daban fe de la expansión de su devoción en la Ciudad Eterna. La entidad del personaje y su marcado carácter de peregrino, hicieron que su presencia fuera más que notable y en algunos casos estos lugares de culto no fueron instituidos por españoles, ni estos se vincularon con ellos. No obstante, gracias también a la literatura del seiscientos, muchas de ellas terminaron identificándose con los miembros de esta nación, que las eligieron como lugar de enterramiento o encargaron misas; incluso, los más pudientes, las ennoblecieron a través de procesos de promoción artística. Además de la ya citada de la iglesia de Santa Marta, especial simbología acompañaba a la capilla situada en la basílica laterana, tan estrechamente vinculada a la corona francesa, por lo que fue considerada como una verdadera «pica en Flandes» ${ }^{28}$.

Entre las situadas en templos con fuertes lazos con la corona española, destacaba la de Santa Maria in Aracoeli. En ella se desarrolló un programa iconográfico en el que se materializaban relatos del Códex Calixtino ${ }^{29}$. También, en la tan hispánica y constantiniana basílica de Santa Croce in Gerusalemme, pues fue título de un buen número de cardenales españoles, en el lado del evangelio, se encontraba la Capilla Compostelana erigida por el español Diego Serrano, escritor apostólico que «demás del retablo del altar quiso que lo manifestasen inscripciones que dicen $[\ldots]\rangle^{30}$. Se encontraba bajo la torre de campanas y el nombre del fundador se hallaba esculpido en ella ${ }^{31}$.

En Santa Maria Sopra Minerva, convento elegido por buena parte de los dominicos españoles para sus estancias romanas y en el que destacó la labor del cardenal fray Juan de Torquemada (1388-1468), también se erigió otra de las capillas dedicadas a Santiago el Mayor. Se encontraba presidida por una pintura del santo que generó un notable impacto en Miguel de Erce, quien la describió como «de cuerpo entero, esclavina con bordón en la mano, rostro hermoso i venerable, i por serlo tanto hize yo sacar de allí la efigie, que imprimí con la oración propia de la Traslación, quando la aprovó por mi diligencia la Congregación de los sacros Ritos» ${ }^{32}$.

\footnotetext{
27 Anselmi Alessandra, "Tota pulchra es amica mea et macula non est in te: la Spagna e l'Immacolata", en L'Immacolata nei rapporti tra l'Italia e la Spagna, ed. Alessandra Anselmi (Roma: De Luca, 2008), 246-281.

${ }^{28}$ Erce, Prueva, 234. Representatividad que se reforzaría con el citado protectorado instituido por Felipe IV.

${ }^{29}$ Ibídem, 234. En referencia a este programa Vázquez Santos Rosa, "Un nuevo catálogo pictórico del Quattrocento italiano: la Tabla del Camerino y el desparecido ciclo jacobeo de Giovenale de Orvieto en Araceli”, Archivo Español de Arte 322 (2008), 105-114.

${ }^{30}$ Erce, Prueva, $234 \mathrm{v}$.

${ }^{31}$ Besozzi Raimondo, La storia della basilica di Santa Croce in Gerusalemme (Roma: Salomoni, 1750), 90.

${ }^{32}$ Erce, Prueva, 234v. Se refiere a la obra de Marcello Venusti que preside esta capilla dedicada al apóstol y también llamada de Lante della Rovere.
} 


\section{PROMOCIÓN ARTÍSTICA DE LOS CARDENALES ESPAÑOLES EN LAS IGLESIAS ROMANAS}

Entre los espacios que generaron esta identidad nacional en Roma, Miguel de Erce también recogió las intervenciones que determinados cardenales llevaron a cabo en las iglesias de las que eran titulares o en aquellas vinculadas con la nación española. Movidos por su piedad y por el deseo de perpetuar su memoria en los templos que le estaban encomendados, todavía hoy se puede rastrear la huella de esta acción en un buen número de iglesias romanas.

El citado cardenal fray Juan de Torquemada lo hizo en el convento de los dominicos de Santa Maria Sopra Minerva ${ }^{33}$. Las obras que emprendió no solo se ajustaron a la iglesia, sino también al claustro, aunque destacó la capilla de la Reina del Cielo, donde en 1460 fundó la cofradía de la Anunqiata. Para la descripción del templo recurrió al baezano Alfonso Chacón (1530-1599). Fray Juan Solano (1504-1580), obispo de Cuzco, fundó en 1580 un colegio de Artes y Sagrada Teología «i ordenó que la lea siempre religioso de la provincia de España [...]» ${ }^{34}$.

Otro caso de notable interés lo encontramos en la figura de fray Juan Álvarez de Toledo (1488-1557), hijo del duque de Alba, obispo de Córdoba y Burgos y arzobispo de Santiago de Compostela y gran promotor de las artes. En 1543 emprendió la reconstrucción de la iglesia de San Lorenzo in Fonte, denominada por Erce in Carcere. Las armas de Álvarez de Toledo quedaron fijadas en el pavimento y en la bóveda ${ }^{35}$.

El título de Santa Croce in Gerusalemme (fig. 6) estuvo estrechamente ligado a púrpura española desde Juan de Carvajal (ca. 1460-1469), que primero lo fue de Sant' Angelo in Pescheria y después de Santa Croce; no obstante, no tenemos noticias de proyectos de promoción artística, si es que los emprendió ${ }^{36}$. Sí, en cambio, las tenemos de otro de los titulares españoles de esta basílica, Pedro González de Mendoza (14281495), arzobispo de Toledo y patriarca de Alejandría, que «renovó con lustre aquel templo de cuya liberalidad da hoy testimonio la magnificencia de las fábricas [...]»; Mendoza promovió la construcción de la tribuna, la nueva techumbre de madera y regaló diversas piezas de plata como un gran relicario para contener el Titulus $\mathrm{Crucis}^{37}$.

33 También lo era para los dominicos de Hispanoamérica. ASCR, Archivio Generale Urbano, Sezione I, Not. Juan Caballero, vol. 202, 1664, julio, 5.

${ }^{34}$ Erce, Prueva, 214v-215.

35 Fue titular de San Pancrazio. Ibídem, 215. Sobre su labor en Roma, véase: Redín Michaus Gonzalo, Pedro Rubiales, Gaspar Becerra y los pintores españoles en Roma, 1527-1600 (Madrid: CSIC, 2007) 206-207.

36 Besozzi, La storia, 117.

${ }^{37}$ Los regalos de plata y ornamentos sagrados fueron los más frecuentes; la custodia de Mendoza competiría con las donadas por el cardenal Alberto de Austria. Para las obras patrocinadas por Mendoza: Besozzi, La storia, 32, 99 y también 118. Sobre la promoción artística en esta basílica, véase: Varaglioni Claudio, Santa Croce in Gerusalemme: La basilica restaurata e l'architettura del Settecento romano (Roma: Bonsignori, 1995), 24-26 y Zuccari Alessandro, "Committenti spagnoli e pittori delle Fiandre nella Roma del Seicento. Istanze politiche attraverso le immagini”, en Dal Razionalismo al Rinascimento per ir quaranta anni di studi di Silvia Danesi Squarzina, ed. Maria Giulia Aurigemma (Roma: Campisano Editore, 2011), 193-194. 
El ornato de Santa Croce aumentó con su sucesor, el también español Bernardino de Carvajal, titular de la basílica entre 1495-1523; el prelado placentino patrocinó la sillería de mármol para el coro e intervino en los mosaicos de la capilla de Santa Elena, de tiempos del emperador Valentiniano III (419-455), asimismo, quedaría retratado en la bóveda de la capilla mayor, arrodillado ante la madre de Constantino el Grande ${ }^{38}$.

A Carvajal le sucedió el italiano cardenal del Monte (1511-1527) y tras él volvió un español, fray Francisco de Quiñones (ca. 1480-1540); su sepultura, realizada por Jacopo Sansovino, se destinó a acoger el sagrario $(1536)^{39}$. Bartolomé de la Cueva y Toledo (1499-1562) comenzó como titular de San Matteo in Merulana y más tarde de San Bartolomeo all' Isola, para finalmente serlo de Santa Croce; en esta basílica intervino en las gradas del altar mayor, la solería y la balaustrada donde se exponían las reliquias ${ }^{40}$. El cardenal Francisco Pacheco (1521-1579), que fue titular primero de Santa Susanna alle Terme di Diocleziano y luego de Santa Croce, lo hizo sobre la capilla de las Reliquias ${ }^{41}$.

Más tarde, el cardenal Gaspar de Borja y Velasco (1580-1645), obispo de Albano y arzobispo de Sevilla, también demostró la preocupación por engrandecer tan simbólico espacio. Lo hizo a través de diversas donaciones como un Crucificado de bronce y piezas de altar realizadas en plata, como la gran lámpara que se utilizaba en las solemnidades, delante de las reliquias ${ }^{42}$. En esta misma línea se manifestó el cardenal Baltasar de Moscoso y Sandoval (1589-1665), obispo de Jaén y arzobispo de Toledo, gran amante de las reliquias y, cómo no, de la magnífica colección que esta basílica atesoraba que «Últimamente las puso en mayor veneración el señor cardenal don Baltasar de Sandoval y Moscoso, obispo de Jaén, mostrando su gran piedad y devoción a aquel celebérrimo santuario su título» ${ }^{43}$. Moscoso también encargó a Simone y

${ }^{38}$ Curiosamente, Miguel de Erce saca de la nómina a Bernardino López de Carvajal. Erce, Prueva, 234v. Besozzi, La storia, 34-35; 76-77; 99-100; 103- y 118-119.

${ }^{39}$ Ibídem, 32-33.

40 Besozzi, La storia, 103-104.

${ }^{41}$ Así lo testimoniaba la siguiente inscripción: «Ex Avctoriate Pij V. Pontificis Maximi/Franciscus Cardinalis Pacecus/ Locvm Hvnc,/In Qvo Sanctissimae Reliquiae conderentvr/extrvxit, dicavitque anno MDLXX». Besozzi, La storia, 93 y 104; también sobre Pacheco: 123-124.

42 Tormo. Monumentos, I, 221-222 y Besozzi, La storia, 98-99. Sobre la labor del cardenal Borja en Roma: García Cueto David, "La acción cultural y el mecenazgo de los cardenales-embajadores de Felipe IV en Roma: Borja y Albornoz", en I rapporti tra Roma e Madrid nei secoli XVI e XVII: arte, diplomacia e política, ed. Alessandra Anselmi (Roma: Gangemi, 2014), 340-361.

${ }^{43}$ Erce, Prueva, 234v. Tampoco podemos olvidar la labor de Moscoso en Santiago de los Españoles, donde costeó el lienzo de la Inmaculada para la capilla de la Concepción. Sobre esta obra: Cacho Marta, "Una embajada concepcionista a Roma y un lienzo conmemorativo de Louis Cousin (1633)" en Arte y diplomacia de la monarquia hispánica en el siglo XVII, ed. José Luis Colomer (Madrid: Centro de Estudios Europa Hispánica, 2003), 419; y la decoración de la capilla: Vázquez Santos Rosa, "La iglesia de San Giacomo degli Spagnoli a la luz del manuscrito 15449 del Archivio Storico Capitolino y otras fuentes del siglo XVII", en Roma y España un crisol de la cultura europea en la Edad Moderna, Actas del Congreso, Real Academia de España en Roma, 8-12 de mayo de 2007, ed. Carlos José Hernando Sánchez (Madrid: Sociedad para la Acción Cultural Exterior, 2007, vol. II), 667-678. Sobre los intereses artísticos del prelado en Roma: Serrano Estrella Felipe, “Obras italianas en la Andalucía de la Edad Moderna”, en Arte italiano en Andalucía. Renacimiento y Barroco, ed. Felipe Serrano Estrella (Granada: Universidad de Granada y Universidad de Jaén, 2017), 62-64. 
Propero Prosperi la realización de, al menos, dos de las campanas para la torre de la basílica en $1631^{44}$.

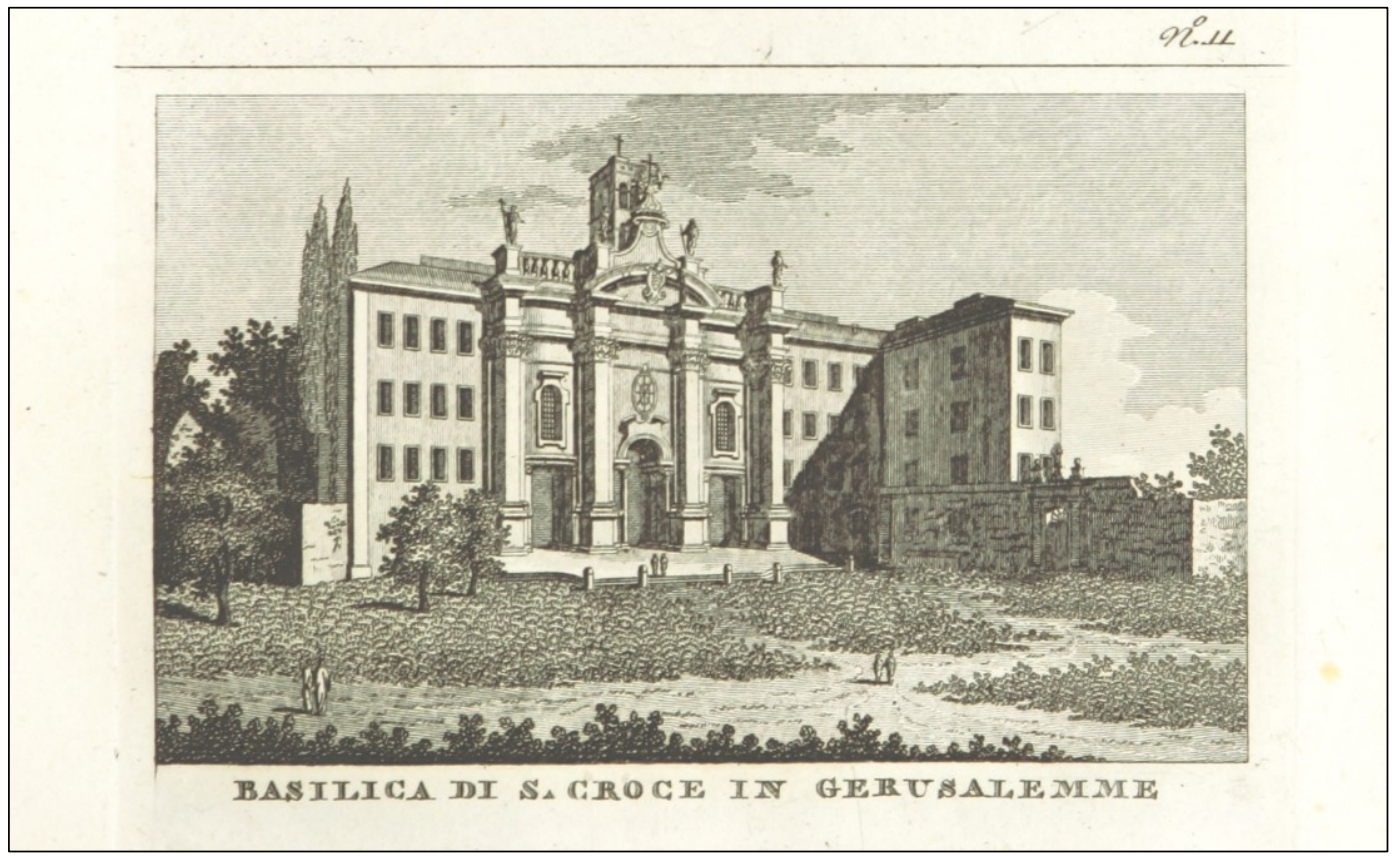

Figura 6. Basilica di S. Croce in Gerusalemme, ca. 1820.

El cardenal Gabriel Trejo y Paniagua (1562-1630) emprendió la restauración de la iglesia de San Bartolomeo all' Isola Tiberina ${ }^{45}$. Luis III de Torres (1551-1609), en 1607, renovó el pavimento y la techumbre de la iglesia de San Pancrazio fuori le Mura, de la que era titular y en la que fue enterrado ${ }^{46}$. El cardenal Bernardo de Sandoval y Rojas, en 1606, dio una nueva imagen a Sant' Anastasia al Palatino, actuando «con grande generositá e magnificenza la ristaurò da fondamenti» ${ }^{47}$; aunque lo más vistoso sería que «la ilustró con un frontispicio i pórtico grandiosos, de que se trata en los libros de Maravillas de Roma» ${ }^{48}$.

${ }^{44}$ Que se conservan en la actualidad: Vasco Roca Sandra, Guide rionali di Roma. Rione XV-Esquilino (Roma, Fratelli Palombi 1967), 30.

45 Tormo, Monumentos, I, 221-222.

46 Tormo, Monumentos, II: 15 y ss. Terzaghi Maria Cristina, "Per Ludovico II de Torres restauratore di San Pancrazio", en Dal Razionalismo al Rinascimento per ir quaranta anni di studi di Silvia Danesi Squarzina, ed. Maria Giulia Aurigemma (Roma: Campisano Editore, 2011), 144-151. Su sobrino Cosme de Torres (1584-1642) también fue cardenal titular de San Pancrazio. Sobre la familia Torres y la labor de Luis III: Soto Artuñedo, “La familia malagueña”, 182.

${ }^{47}$ Cappello Filippo, Brevi notizie dell'antico e moderno stato della Chiesa Collegiata di S. Anastasia di Roma (Roma: Pietro Ferri, 1722), 12-13.

48 Añade que "Últimamente hizo memoria deste edificio el Abad don Fernando Ughello Florentino en las adiciones al Maestro Chacón en la impresión". Erce, Prueva, 227v. Vaccondio subraya la intervención del arzobispo de Toledo en esta iglesia. Vaccondio Juan Baptista, Las cosas maravillosas de la Santa Ciudad de Roma (Roma, Roque Bernabó, 1720), 85. También alude a esta obra: Panciroli Ottavio, 


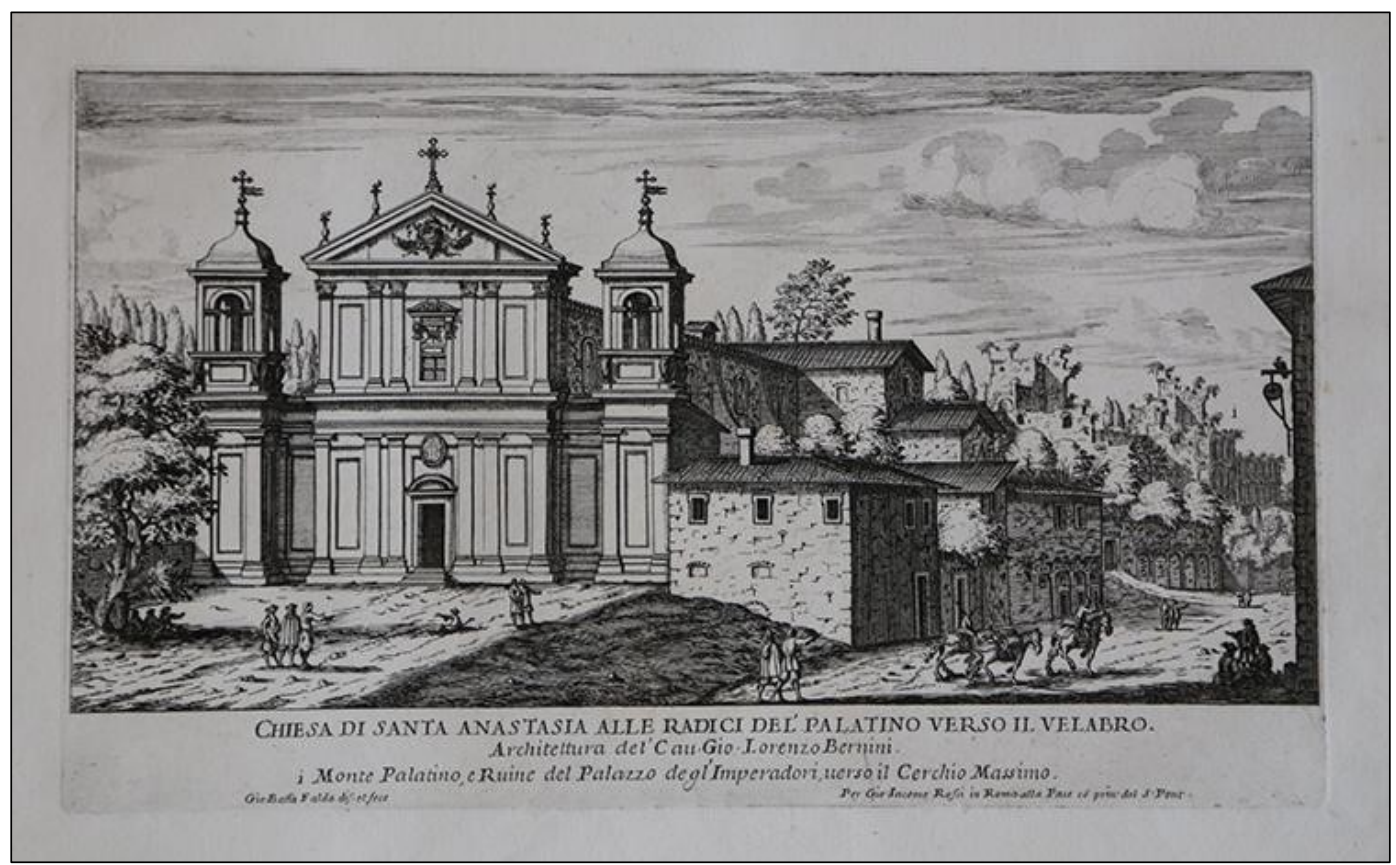

Figura 7. Giovanni Battista Falda, Chiesa di Santa Anastasia alle radici del' Palatino verso il Velabro. Architettura del Cav. Gio Lorenzo Bernini, 1665-1669.

\section{FUNDACIONES ASISTENCIALES DE ESPAÑOLES EN ROMA}

Aunque en una escala inferior, no podemos dejar de lado otras fundaciones españolas en la Urbe. Los deseos de León X (1475-1521) para erigir una casa de recogidas encontraron eco entre los miembros de la nación española. La fundación contó con el apoyo de diferentes caballeros castellanos que fueron enterrados en su iglesia. Fue el caso de Diego de Villoslada, deán de Logroño, que murió en 1520 siendo guardián del monasterio; Juan de Sepúlveda, Alonso de la Torre y Alonso Verdesoto, escritor apostólico. En un primer momento les agregó la iglesia de Santa Lucia, que más tarde cambió su advocación por la de Santa Maria Maddalena delle Convertite; la comunidad de clausura, dispuesta bajo la regla de San Agustín, quedó estrechamente unida a la nación española, en lo que también influyó su estratégica ubicación en el Corso. Miguel de Erce recoge que el rector del templo de Santa Lucia era el hijo de Alonso de Suesa, con lo que se reforzaba esta presencia española desde los orígenes

Tesori nascosti dell'alma città di Roma (Roma: Heredi d'Alessandro Zannetti, 1625), 712. Aunque no se trata de la fachada actual, mandada hacer por Urbano VIII en 1636 y con diseño de Domenico Castello, ya que la promocionada por Sandoval se cayó en 1634 pues no se unió correctamente con la antigua fábrica; no obstante, se mantuvieron las armas de Sandoval en el interior del templo. Ibídem, 12-13 y Fidanza Giovan Battista, Le vicende artistiche della Chiesa di Sant'Anastasia al Palatino nel Seicento: una verifica con la visita apostolica del 1727 (Roma, Ministero per i Beni e le Attività Culturali, Bolletino d'Arte, 2010), 135. 
de la fundación ${ }^{49}$. Las Convertidas del Corso recibieron numerosas limosnas y mandas testamentarias de los españoles residentes en la Urbe ${ }^{50}$.

Tampoco podemos dejar de lado la acción emprendida por San Ignacio de Loyola que, en 1543, creó, también para descarriadas, la Compañía de Nuestra Señora de Gracia, luego convertida en el monasterio de Santa Marta. El fundador de los jesuitas encontró el apoyo de Leonor Osorio Sarmiento, hija del marqués de Astorga y esposa de Juan de Vega (ca. 1507-1558), embajador de Carlos V y virrey de Sicilia. San Ignacio también estuvo detrás de la fundación para doncellas pobres o «hijas de indignas» erigida en el monasterio de Santa Catalina dei Funari, aunque otras fuentes dicen que la instituyó un fraile dominico. Sí es cierto que se sirvió de caballeros romanos y, sobre todo, españoles para tal acción, entre ellos Lorenzo del Castillo, Felipe Ruiz, Alfonso Díaz y el propio Luis de Torres ${ }^{51}$. Precisamente, en esta iglesia de Santa Catalina, una familia española, los Ruiz, con residencia en la Piazza Fiammetta, tenía una capilla que fue diseñada por Jacopo Vignola y con frescos de Girolamo Muziano ${ }^{52}$. También los Torres, con morada en Piazza Navona, poseyeron una capilla en Santa Catalina decorada con pinturas de Marcello Venusti (1573) y allí se enterró Luis II de Torres, arzobispo de Monreale ${ }^{53}$.

Para terminar, recordaremos que en la Piazza Colonna estaba el hospital de Santa Maria della Pietà o Dei Pazzarelli para enfermos mentales, aunque en un principio destinado a peregrinos pobres. También fue fundado por españoles, concretamente en 1548 por el licenciado Fernando Ruiz, cura de Sevilla, amigo de San Ignacio de Loyola, que contó con la ayuda del doctor García Serrano, natural de Medinaceli, protonotario crucífero apostólico, y los navarros Ángel Brano y su hijo Diego. El cuarto de mujeres de esta institución había sido erigido gracias a la hispano-portuguesa, Catalina Parda. En relación con esta realidad asistencial, y de nuevo en un espacio particularmente

\footnotetext{
${ }^{49}$ En 1520 se quemó y se restauró en 1617.

${ }^{50}$ ASCR, Archivio Generale Urbano, Sezione I, Not. Juan Caballero, vol. 202, Roma, 1664, mayo, 29.

51 Sobre esta institución: Camacho Martínez Rosario, "La Compañía de las Pobres Vírgenes Miserables de Roma y el patronazgo de don Luis de Torres", en Docta Minerva. Homenaje a la profesora Luz de Ulierte Vázquez, ed. Felipe Serrano Estrella (Jaén: Universidad de Jaén, 2011), 471-478.

52 En relación con esta capilla: Tosini Patrizia, Girolamo Muziano 1532-1592 dalla Maniera alla natura (Roma: Bozzi, 2008), 360-366.

${ }^{53} \mathrm{El}$ arzobispo de Salerno Luis de Torres (†1553) pidió que su cuerpo se depositara en esta iglesia antes de ser llevado a Málaga; las obras de ennoblecimiento del templo las emprendió su sobrino Luis de Torres, arzobispo de Monreale, que encargó a Marcello Venusti las pinturas. Durante el cardenalato de Federico Cesi (1560-1565) la iglesia fue reestructurada. Sobre esta capilla: Antellini Simona, "Gli stucchi e i dipinti in Roma delle volte delle Cappelle Torres e Riussi in Santa Caterina de' Funari e della Loggia detta «del Primaticcio» in Palazzo di Firenze", en Superfici dell'architettura: le finiture, ed. Guido Biscontin y Stefano Volpin (Padova, Libreria Progetto, 1990), 139-149; Quattrone Stefania, "Santa Caterina dei Funari”, Roma Sacra 14 (1998), 29 y 64; D’Amelio Anna, "La famiglia de Torres e Marcello Venusti", en Dal Razionalismo al Rinascimento per ir quaranta anni di studi di Silvia Danesi Squarzina, ed. Maria Giulia Aurigemma (Roma: Campisano Editore, 2011), 101-106. Anselmi nos dice que Venusti y Muziano eran pintores apreciados por los españoles, que mandaron obra a España. Venusti pintó para Sant'Antonio dee Portoghesi y para la capilla de San Miguel en San Giacomo degli Spagnoli. Anselmi, Le chiese, 28. Sobre la figura de Luis II de Torres: Soto Artuñedo, "La familia", 169-179.
} 
vinculado a la clerecía española, el Borgo Pio, Cristóbal de Cabrera, sacerdote de Palencia, fundó en sus casas un alojamiento para doce mujeres peregrinas. En él tenían preferencia las españolas y su patronato recayó sobre los diputados de la cofradía del Santísimo Sacramento de San Pietro; además dotó un pan para cada una al día, limosna que fue doblada por Pedro de Alarcón y Granada en 1636, «descendiente de los reyes antiguos de ella, con que tienen más pan, de lo que ordinariamente come una mujen $»^{54}$.

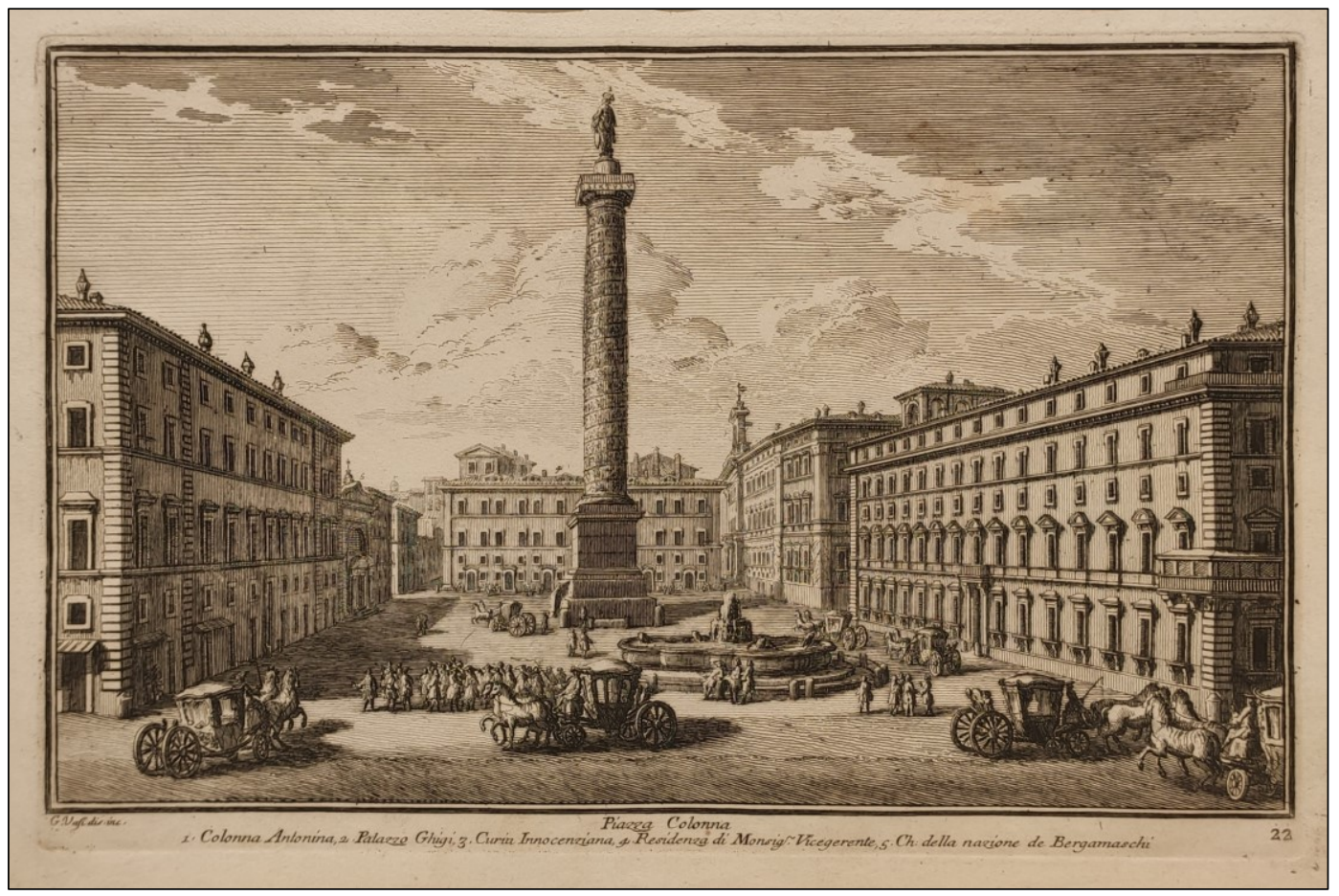

Figura 8. Giuseppe Vasi, Piazza Colonna, 1760 (el hospital de Santa Maria della Pietà se había transformado en iglesia de la Nazione de Bergamaschi, 5)

\section{CONCLUSIÓN}

Como hemos podido comprobar, existió un marcado interés por extender la identidad hispánica en Roma más allá de las denominadas iglesias nacionales. La obra de Miguel de Erce (1648) da buena prueba de ello. A través de la descripción de los templos vinculados a los reinos de la Península Ibérica, las casas mendicantes, los lugares dedicados a Santiago el Mayor, las intervenciones de los cardenales españoles y las fundaciones asistenciales alentadas por los miembros de esta nación, Erce nos ofrece una completa visión de la Roma española, aunque en determinados casos bastante exagerada -particularmente con los lugares santiaguistas-. Seguramente,

${ }^{54}$ Erce, Prueva, 224v. Véase también: Fanucci Camillo, Trattato di tutte l'Opere pie dell'alma città di Roma (Roma: Lepido Facii y Stefano Paolini, 1601), 56-58. 
muchas de estas instituciones pasaron desapercibidas para un buen número de los españoles residentes o peregrinos en la Urbe, sin embargo, en la mayoría de los casos, evidencian la vitalidad de la Roma española de la Edad Moderna. 


\section{REFERENCIAS BIBLIOGRÁFICAS}

Aguado Francisco, Las fundaciones de España en Roma y las leyes italianas de desamortización (Roma: Tipografía Romana, 1875).

Aliaga Asensio, Pedro, "Alle origini di Santa Marta", L'Osservatore Romano (29.1.2016), 4.

Anselmi Alessandra, "Tota pulchra es amica mea et macula non est in te: la Spagna e l'Immacolata", en L'Immacolata nei rapporti tra l'Italia e la Spagna, ed. Alessandra Anselmi (Roma: De Luca, 2008), 239-300.

Anselmi Alessandra, Le chiese spagnole nella Roma del Seicento e del Settecento (Roma: Gangemi, 2012).

Anselmi Alessandra, "El mecenazgo artístico en las iglesias de las naciones de la monarquía española en Roma en los siglos XVI-XVII. Estado actual de los estudios" en Las corporaciones de nación en la monarquía hispánica (1580-1750). Identidad, patronazgo y redes sociales, ed. Benardo J. García García y Óscar Recio Morales (Madrid: Fundación Carlos de Amberes, 2014), 245-264.

Antellini Simona, "Gli stucchi e i dipinti in Roma delle volte delle Cappelle Torres e Riussi in Santa Caterina de' Funari e della Loggia detta «del Primaticcio» in Palazzo di Firenze", en Superfici dell'architettura: le finiture, ed. Guido Biscontin y Stefano Volpin (Padova, Libreria Progetto, 1990), 139-149.

Barrio Gozalo Maximiliano, "La Iglesia y Hospital de Santiago de los Españoles de Roma y el patronato real en el siglo XVII", Investigaciones Históricas: Época moderna y contemporánea 24 (2004), 53-76.

Besozzi Raimondo, La storia della basilica di Santa Croce in Gerusalemme (Roma: Salomoni, 1750).

Bodart Diane H., "Le guerre des statues. Monuments de rois de France et d'Espagne à Rome au XVIIe siècle", en Roma y España un crisol de la cultura europea en la Edad Moderna, Actas del Congreso, Real Academia de España en Roma, 8-12 de mayo de 2007, ed. Carlos José Hernando Sánchez (Madrid: Sociedad para la Acción Cultural Exterior, 2007, vol. II), 679-694.

Bossi Gaetano, La Chiesa di Santa Marta al Vaticano. Monografia storica (Roma: Tipografia Poliglotta della S. C. di Propanda, 1883).

Cacho Marta, "Una embajada concepcionista a Roma y un lienzo conmemorativo de Louis Cousin (1633)" en Arte y diplomacia de la monarquia bispánica en el siglo XVII, 
ed. José Luis Colomer (Madrid: Centro de Estudios Europa Hispánica, 2003), 415-428.

Camacho Martínez Rosario, "La Compañía de las Pobres Vírgenes Miserables de Roma y el patronazgo de don Luis de Torres", en Docta Minerva. Homenaje a la profesora Luz de Ulierte Vázquez, ed. Felipe Serrano Estrella (Jaén: Universidad de Jaén, 2011), 471-478.

Cappello Filippo, Brevi notizie dell'antico e moderno stato della Chiesa Collegiata di S. Anastasia di Roma (Roma: Pietro Ferri, 1722).

Carrió-Invernizzi Diana, "La estatua de Felipe IV en Santa Maria Maggiore y la embajada romana de Pedro Antonio de Aragón (1664-1666)", Roma moderna e contemporanea revista interdicisplinare di storia 1-3 (2007), 255-270.

Carrió-Invernizzi Diana, El gobierno de las imágenes. Ceremonial y mecenazgo en la Italia española de la segunda mitad del siglo XVII (Madrid: Tiempo Emulado, 2008).

Carrió-Invernizzi Diana, "Los catalanes en Roma y la iglesia de Santa María de Montserrat (1640-1670)", Pedralbes 28 (2008b), 571-584.

Carrió-Invernizzi Diana, "Santiago de los Españoles en Plaza Navona (Siglos XVIXVII)", en Piazza Navona, ou Place Navone, la plus belle \& la plus grande, Jean François Bernard (Roma: École Française de Rome, 2014), 635-655.

Cola Maria Celeste, "Santa Maria d'Itria o di Constantinopoli”, Roma Sacra 5 (1996), 26-29.

D’Amelio Anna, "La famiglia de Torres e Marcello Venusti”, en Dal Razionalismo al Rinascimento per ir quaranta anni di studi di Silvia Danesi Squarzina, ed. Maria Giulia Aurigemma (Roma: Campisano Editore, 2011), 101-106.

Dandelet Thomas James, Spanish Rome 1500-1700 (New Haven-London: Yale University Press, 2001).

Erce Ximénez Miguel de, Prueva evidente de la predicación del apóstol Santiago el Mayor en los Reinos de España (Madrid: Alonso de Paredes, 1648).

Espadas Burgos Manuel, Buscando a España en Roma (Barcelona-Madrid: Lunwerg, 2006).

Falomir, Miguel, "Sebastiano and «Spanish taste»" en Sebastiano del Piombo, 14851547, Cat. Exp. Palazzo Venezia, Roma, 8 de febrero-18 de mayo de 2008, ed. Claudio Strinari y Bernd Wolfgang Lindermann (Milán, Federico Motta, 2008), 67-71. 
Fanucci Camillo, Trattato di tutte l'Opere pie dell'alma città di Roma (Roma: Lepido Facii y Stefano Paolini, 1601).

Fernández Alonso Justo, "Las iglesias nacionales de España en Roma. Sus orígenes", Anthologica Annua 4 (1956), 9-96.

Fernández Alonso Justo, "Santiago de los Españoles de Roma en el siglo XVI", Anthologica Annua, 6 (1958), 266-285.

Fernández Alonso Justo, S. Maria di Monserrato (Roma: Marietti, 1968).

Fernández Alonso Justo, "El cardenal Francisco de Toledo, S. J., y su fundación en Santa María la Mayor", Anthologica annua 37 (1990), 363-380.

Fidanza Giovan Battista, Le vicende artistiche della Chiesa di Sant'Anastasia al Palatino nel Seicento: una verifica con la visita apostolica del 1727 (Roma, Ministero per i Beni e le Attività Culturali, Bolletino d'Arte, 2010).

García Hernán Enrique, "La iglesia de Santiago de los Españoles en Roma: trayectoria de una institución", Anthologica Annua 42 (1995), 297-363.

García Cueto David, "El mecenazgo de los embajadores de Felipe IV en los conventos de Roma: política, prestigio y devoción en la Ciudad Eterna durante el siglo XVII", en La corte en Europa. Política y religión (siglos XVI-XVIII), ed. José Martínez Millán et alii (Madrid: Polifemo, 2012, vol. II), 1661-1697.

García Cueto David, "La acción cultural y el mecenazgo de los cardenales-embajadores de Felipe IV en Roma: Borja y Albornoz", en I rapporti tra Roma e Madrid nei secoli XVI e XVII: arte, diplomacia e política, ed. Alessandra Anselmi (Roma: Gangemi, 2014), 340-361.

Goñi Gaztambide José, "Bernardino López de Carvajal y las bulas alejandrinas", Anuario de Historia de la Iglesia, 1 (1992), 93-112.

Ostrow Steven F., "Gianlorenzo Bernini, Girolamo Lucenti and the Statue of Philip IV in S. Maria Maggiore. Patronage and politics in Seicento Rome", Art Bulletin 73 (1991), 89-118.

Panciroli Ottavio, Tesori nascosti dell'alma città di Roma (Roma: Heredi d'Alessandro Zannetti, 1625).

Pietrangeli Carlo, "Ricordo di una chiesa distrutta: Santa Marta al Vaticano", Bollettino Monumenti Musei e Gallerie Pontificie" 5 (1984), 91-111. 
Quattrone Stefania, “Santa Caterina dei Funari”, Roma Sacra 14 (1998), 29 y 64.

Redín Michaus Gonzalo, Pedro Rubiales, Gaspar Becerra y los pintores españoles en Roma, 1527-1600 (Madrid: CSIC, 2007).

Rivera de las Heras José Ángel, La Iglesia Nacional Española de Santiago y Montserrat de Roma (Madrid: Instituto Español de Historia Eclesiástica, 2020).

Serrano Estrella Felipe, “Obras italianas en la Andalucía de la Edad Moderna”, en Arte italiano en Andalucía. Renacimiento y Barroco, ed. Felipe Serrano Estrella (Granada: Universidad de Granada y Universidad de Jaén, 2017), 7-67.

Serrano Estrella Felipe, "Conventos y hospicios de las órdenes mendicantes española en la Roma moderna”, BSAA arte 84 (2018): 219-254.

Soto Artuñedo Wenceslao, "La familia malagueña «De Torres» y la Iglesia", Isla de Arriarán 19 (2002), 163-191.

Terzaghi Maria Cristina, "Per Ludovico II de Torres restauratore di San Pancrazio", en Dal Razionalismo al Rinascimento per ir quaranta anni di studi di Silvia Danesi Squarzina, ed. Maria Giulia Aurigemma (Roma: Campisano Editore, 2011), 144-151.

Tormo Elías, Monumentos de españoles en Roma, y de portugueses e bispanoamericanos (Madrid: Ministerio de Asuntos Exteriores, 1942).

Tosini Patrizia, Girolamo Muqiano 1532-1592 dalla Maniera alla natura (Roma: Bozzi, 2008).

Vaccondio Juan Baptista, Las cosas maravillosas de la Santa Ciudad de Roma (Roma, Roque Bernabó, 1720).

Vaquero Piñeiro Manuel, "L'ospedale della nazione castigliana in Roma tra medioevo ed età moderna", Roma moderna e contemporánea 1 (1993), 57-81.

Vaquero Piñeiro Manuel, "Una realtá nazionale composita: comunità e chiese «spagnole» a Roma", en Roma capitale (1447-1527), Atti del IV convegno di studio del Centro di Studi sulla Civiltà del Tardo Medioevo, 27-31 ottobre 1992, ed. Sergio Gensini (San Miniato, Pacini, 1994), 473-491.

Vaquero Piñeiro Manuel, "I funerali romani del principe Giovanni e della regina Isabella di Castiglia. Rituale politico al servizio della monarchia spagnola", en 
Roma di fronte all'Europa al tempo di Alessandro VI, eds. Maria Chiabó, Silvia Maddalo, Massimo Miglio y Anna Maria Oliva (Roma: Ministero per i beni e le attività culturali, 2001, vol. 2), 641-655.

Varaglioni Claudio, Santa Croce in Gerusalemme: La basilica restaurata e l'architettura del Settecento romano (Roma: Bonsignori, 1995).

Vasco Roca Sandra, Guide rionali di Roma. Rione XV - Esquilino (Roma, Fratelli Palombi 1967).

Vázquez Santos Rosa, "La iglesia de San Giacomo degli Spagnoli a la luz del manuscrito 15449 del Archivio Storico Capitolino y otras fuentes del siglo XVII", en Roma y España un crisol de la cultura europea en la Edad Moderna, Actas del Congreso, Real Academia de España en Roma, 8-12 de mayo de 2007, ed. Carlos José Hernando Sánchez (Madrid: Sociedad para la Acción Cultural Exterior, 2007, vol. II), 667-678.

Vázquez Santos Rosa, "Un nuevo catálogo pictórico del Quattrocento italiano: la Tabla del Camerino y el desparecido ciclo jacobeo de Giovenale de Orvieto en Araceli”, Archivo Español de Arte 322 (2008), 105-114.

Vázquez Santos Rosa, "Primeras conclusiones sobre el culto y la iconografía de Santiago el Mayor en la ciudad de Roma", Archivo Español de Arte 329 (2010): $1-22$.

Visceglia Maria Antonietta, "Vi è stata una «Roma spagnola»", Roma moderna e contemporanea 11 (2003), 313-323.

Visceglia Maria Antonietta, "Rome e la Monarchia Cattolica nell'età dell'egemonia spagnola in Italia: un bilancio storiografico", en Roma y España un crisol de la cultura europea en la Edad Moderna, Actas del Congreso, Real Academia de España en Roma, 8-12 de mayo de 2007, ed. Carlos José Hernando Sánchez (Madrid: Sociedad para la Acción Cultural Exterior, 2007, vol. I), 53-77.

Visceglia Maria Antonietta, Roma papale e la Spagna. Diplomatici nobili e religiosi tra due corti, (Roma: Bulzoni, 2010).

Zuccari Alessandro, "Committenti spagnoli e pittori delle Fiandre nella Roma del Seicento. Istanze politiche attraverso le immagini”, en Dal Razionalismo al Rinascimento per ir quaranta anni di studi di Silvia Danesi Squarzina, ed. Maria Giulia Aurigemma (Roma: Campisano Editore, 2011), 193-204. 
Recibido: 31 de agosto de 2020 Aprobado: 25 de septiembre de 2020 